\title{
Temperature-driven changes of pollinator assemblage and activity of Megaleranthis saniculifolia (Ranunculaceae) at high altitudes on Mt. Sobaeksan, South Korea
}

Hakbong Lee and Hyesoon Kang ${ }^{*}$ (D)

\begin{abstract}
Background: Temperature-driven variation in pollinator assemblage and activity are important information, especially at high altitudes, where rising temperature trends exceed global levels. Temporal patterns of pollinators in a flowering season can be used as a proxy to predict the changes of high-altitude plants' mutualistic relationships. We observed a spring temperature change in one population of a high-altitude endemic species, Megaleranthis saniculifolia on Mt. Sobaeksan, and related it to pollinator assemblage and activity changes.
\end{abstract}

Methods: This study was conducted at two sites, each facing different slopes (NE and NW), for two times in the spring of 2013 (early-flowering, April 27-28, vs. mid-flowering, May 7-8, 2013). We confirmed that the two sites were comparable in snowmelt regime, composition of flowering plants, and flower density, which could affect pollinator assemblage and activity. Pollinator assemblage and activity were investigated at three quadrats ( $1 \mathrm{~m}^{2}$ with 5 -m distance) for each site, covering a total of 840 min observation for each site. We analyzed correlations between the temperature and visitation frequency.

Results: Twelve pollinator species belonging to four orders were observed for M. saniculifolia at both sites during earlyand mid-flowering times. Diptera (five species) and hymenopteran species (four species) were the most abundant pollinators. Pollinator richness increased at both sites toward the mid-flowering time [early vs. mid $=7$ (NE) and 3 (NW) vs. 9 (NE) and 5 (NW)]. Compared to the early-flowering time, visitation frequency showed a fourfold increase in the mid-flowering time. With the progression of spring, major pollinators changed from flies to bees. Upon using data pooled over both sites and flowering times, hourly visitation frequency was strongly positively correlated with hourly mean air temperature.

Conclusions: The spring temperature change over a relatively brief flowering period of $M$. saniculifolia at high altitudes can alter pollinator assemblages through pollinator dominance and visitation frequency changes. Thus, this study emphasizes information on intra- and inter-annual variations in the mutualistic relationship between pollinators and $M$. saniculifolia to further assess the warming impacts on M. saniculifolia's reproductive fitness.

Keywords: High altitude, Megaleranthis saniculifolia, Pollinator assemblage, Spring flowering, Temperature change

\footnotetext{
* Correspondence: hkang@sungshin.ac.kr

Department of Biology, Sungshin University, 55, Dobong-ro 76ga-gil,

Gangbuk-gu, Seoul 01133, South Korea
}

(c) The Author(s). 2018 Open Access This article is distributed under the terms of the Creative Commons Attribution 4.0 International License (http://creativecommons.org/licenses/by/4.0/), which permits unrestricted use, distribution, and reproduction in any medium, provided you give appropriate credit to the original author(s) and the source, provide a link to the Creative Commons license, and indicate if changes were made. The Creative Commons Public Domain Dedication waiver (http://creativecommons.org/publicdomain/zero/1.0/) applies to the data made available in this article, unless otherwise stated. 


\section{Background}

Variation in pollinator assemblage and activity along temperature gradients is important information, especially at high altitudes, where annual mean temperatures increase more rapidly than global levels as seen during the last few decades (IPCC 2013). Such information helps infer possible changes in future pollinator assemblages and activity due to climate change (Hegland et al. 2009). Recently, the global trend of rising temperatures has resulted in reduced pollinator abundance, which can threaten the survival of high-altitude plants that highly depend on them (Lefebvre et al. 2018). Altitudinal scale investigation can be a good proxy for inferring the impact of temperature change on pollinator assemblage and activity as temperature varies with elevation (Hegland et al. 2009). Many researchers have reported that pollinator assemblages tend to change from bees at lower altitudes (Totland 1993; Hoiss et al. 2012; Zhao and Wang 2015) to flies at higher altitudes (Arroyo et al. 1982; Totland 1993; Lázaro et al. 2008; Inouye et al. 2015; Wagner et al. 2016) and that their activity decreases with elevation (Arroyo et al. 1985; Primack and Inouye 1993; Bingham and Orthner 1998; Zhao and Wang 2015). However, relatively few studies have focused on how temperature changes during a flowering season affect high-altitude plant-pollinator assemblage and activity (Primack 1978; Mizunaga and Kudo 2017). Such research is critical to predict the future status of high-altitude plants, especially those being dependent upon activities of pollinators that are sensitive to temperature changes in early spring (e.g., Totland 1994a; Hirao et al. 2006; Thomson 2010; Mizunaga and Kudo 2017).

Megaleranthis saniculifolia is a rare endemic perennial plant, which is distributed only on Korea's high mountains and moist habitats (770-1440 masl; Jang et al. 2009). $M$. saniculifolia is classified as "endangered" in the IUCN Red List of Threatened Species (Kim et al. 2016). Among the existing populations in Korea, Mt. Sobaeksan (1300 m a.s.l.) hosts the largest population of M. saniculifolia (Yoo et al. 1999) and thus entails high priority for its conservation. As pollen flow for this plant was assumed to be mostly mediated by insect pollinators (i.e., Anthomyiid, Bombyliid, and Tachinid flies; Choi 2002), variations in pollinator assemblages and activities are likely to have substantial impacts on its fitness. To date, no pollinator survey of M. saniculifolia in the Sobaeksan population has been conducted at different spatio-temporal scales nor under different temperature regimes (see Choi 2002). Indeed, pollinator visitation patterns have never been explored for any high altitude plants in Korea.

We investigated $M$. saniculifolia's pollinator assemblage and activity throughout the early- and mid-flowering times with contrasting temperature regimes. Pollinator assemblage and activity are not only influenced by temperature but also by many diverse site-specific conditions, such as snow regime (Kudo 1996), flowering plant compositions (Ebeling et al. 2008), and flower density at the community level (Hegland and Boeke 2006). Thus, we chose two sites on different slopes (NE and NW) that were comparable in temperature, snow regimes, flowering plant compositions, and flower density and explored the impact of temperature rise for a short time period in relation to changes in $M$. saniculifolia's pollinator assemblage and activity.

\section{Methods}

\section{Study species}

Megaleranthis saniculifolia (Ranunculaceae) has dish-like actinomorphic flowers that bloom in March or April. The flower consists of 5 to 6 white sepals and 8 to 12 yellowish nectariferous petals with yellow (Yoo et al. 1999; Lee et al. 2017). The flower has apocarpous carpels (range $=3$ to 11; Lee et al. 2017) in the center which are surrounded by many stamens (range $=13$ to 42 ; Son et al. 2011). The Sobaeksan population blooms in April when the snow starts to melt, and at this time, the cold weather extends the individual flower longevity up to 11 to 15 days (Lee et al. 2017). Seed production is mostly achieved by outcross pollination, resulting in 6.4-fold higher in seed set than selfing treatments (control vs. hand-selfing $=71.9 \%$ vs. $11.3 \%$, Lee et al. 2017). Nonetheless, some inbreeding occurs in the Sobaeksan population and other large populations in Korea (Jeong et al. 2010).

\section{Study site}

This study was conducted on the top of the Sobaeksan National Park (1345-1361 m asl) in 2013 when the snow started to melt in mid-April and ended the process in early May. Taxus cuspidata, Cornus controversa, and Betula ermanii were the dominant trees in the study area, and some perennial forbs (e.g., M. saniculifolia, Anemone koraiensis, and Meehania urticifolia) occupied the lower layer of the forest (Yoo et al. 1999; Choi 2002; Lee et al. 2017).

To minimize any damage to the population and to incorporate spatial variation in pollinator assemblage and activity, we selected two sites on different slopes (NE site-36 $57^{\prime} 31.0^{\prime \prime} \mathrm{N}, 128^{\circ} 28^{\prime} 37.0^{\prime \prime} \mathrm{E}, 1361 \mathrm{~m}$ asl; NW site-36 $57^{\prime} 32.0^{\prime \prime} \mathrm{N}, 128^{\circ} 28^{\prime} 32.0^{\prime \prime}$ E, $1345 \mathrm{~m}$ asl). The two sites have identical snow regimes (the same onset of snowmelt), and only $M$. saniculifolia was flowering at both sites. We installed equal-sized quadrats $(20 \times 20$ $\mathrm{m})$ at the two sites then subdivided it into $2516-\mathrm{m}^{2}$ quadrats to measure flower density. As a result, mean flower densities for the $1-\mathrm{m}^{2}$ quadrat in the center of each of the subquadrats $\left(16 \mathrm{~m}^{2}\right)$ were not significantly different between the two sites (NE vs. NW $=24.6 \pm 2.5$ vs. $23.5 \pm 2.5, t=0.308, \mathrm{df}=48, P=0.759)$. After we confirmed morning temperatures three times a week in the sites, we decided two survey times showing a pronounced difference in mean air temperature for $7 \mathrm{~h}$ 
(1000 to $1600 \mathrm{~h}$ ), which corresponded to M. saniculifolia's early- (April 27-28, 2013) and mid- (May 7-8) flowering times (early vs. $\mathrm{mid}=15.8 \pm 0.67^{\circ} \mathrm{C}$ vs. $27.0 \pm 0.83^{\circ} \mathrm{C}, t=$ 10.486, $\mathrm{df}=54, P<0.001$; Fig. 1 ). Throughout this study, we employed only daytime air temperature from 1000 to 1600 h. Using a data logger (Onset $\mathrm{HOBO}^{\circ}$ Pendant UA-002-64), we confirmed that the two sites did not differ in mean air temperature for $7 \mathrm{~h}$ during the two flowering times (NE vs. $\mathrm{NW}=21.2 \pm 1.37^{\circ} \mathrm{C}$ vs. $21.6 \pm 1.25^{\circ} \mathrm{C}, t=0.257, \mathrm{df}=54, P$ $=0.798)$. Since the mean air temperature did not differ between the sites, but differed between the flowering times, temperature data at the two sites were pooled into each of the flowering times (early and mid).

\section{Pollinator assemblage and activity}

Pollinator surveys were conducted at three quadrats (1 $\mathrm{m}^{2}$ with 5-m distance) for each site (NE and NW). Prior to the survey in the early-flowering time (April 27-28), we selected quadrats in which the total number of flowers blooming between the two sites did not differ (NE vs. $\mathrm{NW}=22,30$, and 25 vs. 19,26 , and 32 ). In the mid-flowering time (May 7-8), we rearranged the three quadrats to include the newly bloomed flowers. There was no difference in the total number of flowers between sites ( $\mathrm{NE}$ vs. $\mathrm{NW}=29,31$, and 40 vs. 24,24 , and 42 ). However, the total number of flowers in the three quadrats of each site increased toward the mid-flowering time (early vs. mid $=77$ vs. 100 ). Before the survey, we installed a temperature logger (Onset $\mathrm{HOBO}^{\circ}$ Pendant

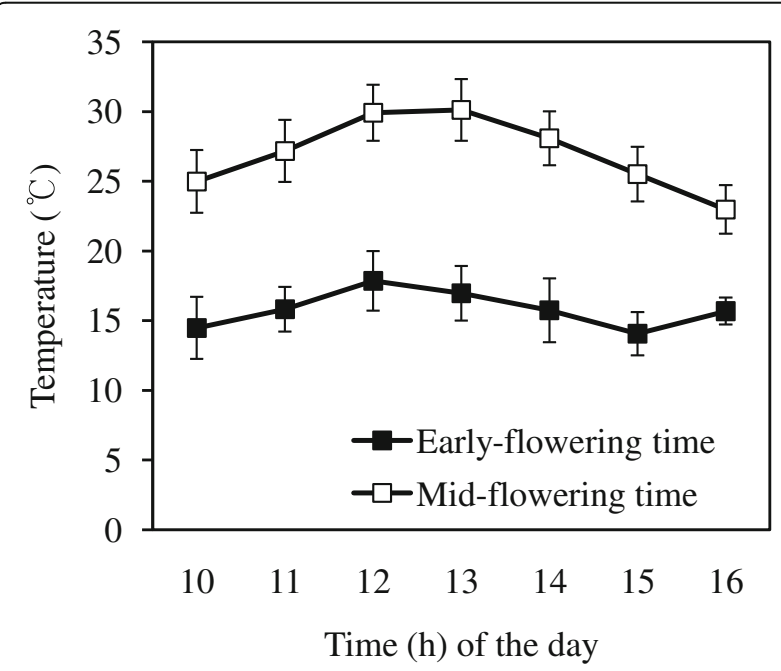

Fig. 1 Daily mean air temperature ( \pm SE) of early-flowering (black square) (April 27-28, 2013) and mid-flowering times (white square) (May 7-8, 2013) of Megaleranthis saniculifolia on Mt. Sobaeksan. Since the temperatures at the two sites (NE and NW) were almost identical, temperature data for the two sites were pooled into each of the flowering time (early and mid). Mean air temperatures in early-flowering and mid-flowering times were $15.8 \pm 0.677^{\circ} \mathrm{C}$ and $27.0 \pm 0.83^{\circ} \mathrm{C}$, respectively
UA-002-64) at each $1-\mathrm{m}^{2}$ quadrat, parallel to the flower height. The survey was carried out at an hourly interval from 1000 to $1600 \mathrm{~h}$, during which we spent $10 \mathrm{~min}$ observing pollinator visits for each quadrat, covering a total of 840 min observation per site. Only insect visitors that contacted the reproductive organs (e.g., anther or stigma) or foraged floral nectar (detected by neutral red) were counted and regarded as effective pollinators. We counted the total number of flowers that each insect visited within our $1 \mathrm{~m}^{2}$ quadrat for $10 \mathrm{~min}$, summed the hourly visitation frequency (i.e., total number of flowers visited within the quadrat) from the three quadrats, and compared visitation rates (visits per flower per hour) between the two flowering times. We also investigated the correlation between hourly mean air temperature and hourly visitation frequency using data pooled over sites and flowering times. For each of the collected insect visitors, at least three specimens were produced, but only one specimen was produced for less frequent visitors. The insect specimens were identified at a species level, while family level identification was done when species identification was impossible.

\section{Statistical analysis}

The difference in mean flower density and mean air temperature between sites and flowering times was examined using $t$ test. A simple linear regression analysis was done to assess the relationship between hourly mean air temperature and hourly visitation frequency. The hourly visitation frequency was square-root transformed to meet the normality assumption for the parametric test. All tests were conducted at the 0.05 significance level using $R$ ver. 3.4.3 ( $\mathrm{R}$ Core Team 2017). All means are provided with one SE throughout this paper.

\section{Results}

Pollinator assemblage of the Sobaeksan population

Twelve pollinator species (11 families in 4 orders) were observed over the two flowering times (April 27-28 and May 7-8, 2013) at the two sites (NE and NW) (Fig. 2). For the Sobaeksan population of M. saniculifolia, $75 \%$ of the visiting insects were dipteran (5 species) and hymenopteran species (4 species), and the others ( 3 species) consisted of one hemipteran (Cicadellidae) and 2 lepidopteran species (Hemaris affinis and Luehdorfia puliloi). Insect visitors of M. saniculifolia foraged for pollen or flower nectar, and nectar was detected at the base of the nectariferous petal (Fig. 2). Although the two sites did not differ in mean air temperature, snowmelt regime, composition of flowering plants, and flower density at the community level, they differed in pollinator assemblages. Pollinator richness was approximately twofold higher for the NE site than the NW site $[\mathrm{NE}$ vs. NW = 11 species (Hemiptera, Hymenoptera, Diptera, and Lepidoptera) vs. 6 species (Hymenoptera and Diptera); Fig. 3]. While Anthomyiidae sp. 1, Bombylius 


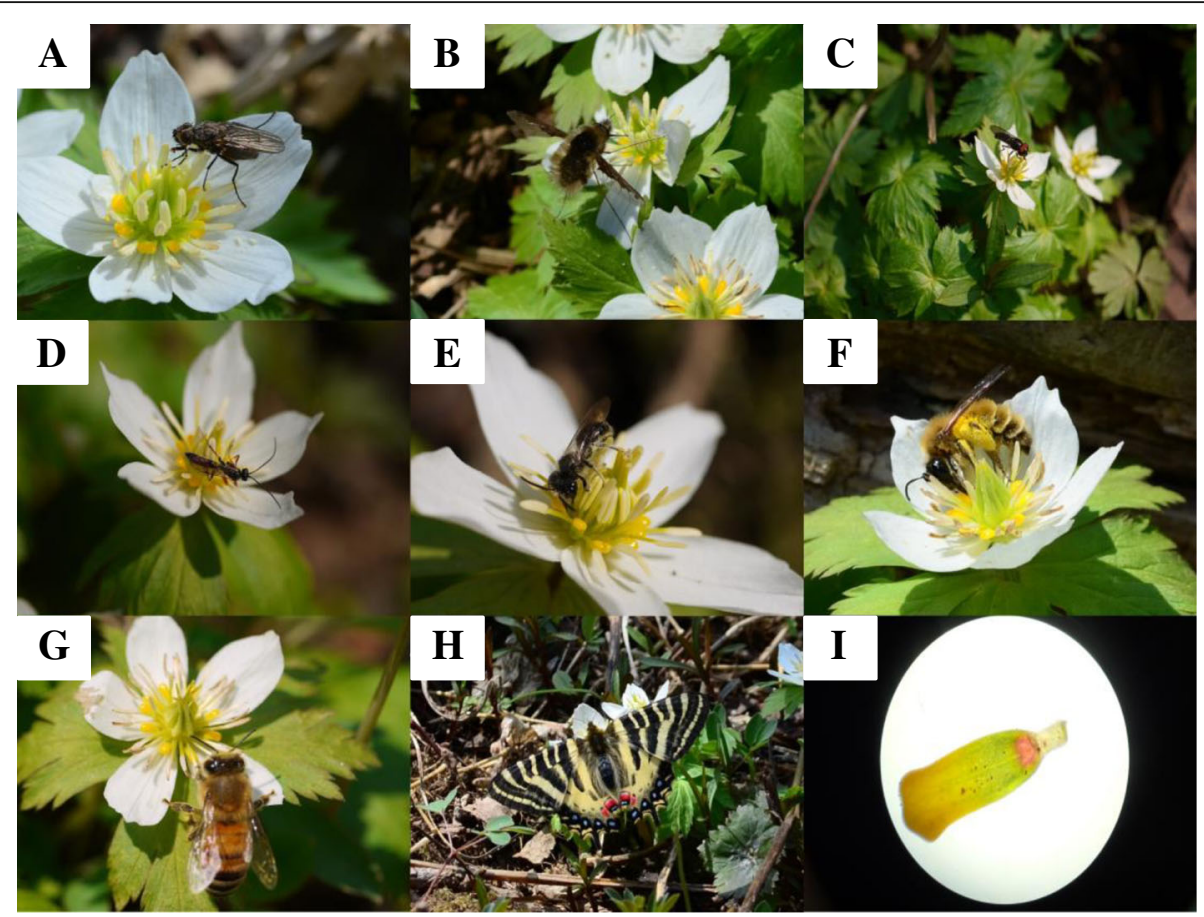

Fig. 2 Insect visitors foraging for M. saniculifolia's pollen or nectar in the study sites on Mt. Sobaeksan. a Anthomyiidae sp. 1. b Bombylius major. c Melanostoma scalare. $\mathbf{d}$ Vulgichneumon suigensis. e Andrena sp. 1 (male). f Andrena sp. 2 (female). g Apis mellifera. $\mathbf{h}$ Luehdorfia puziloi. Most visitors suck nectar from the base part of the nectariferous petals stained in a neutral red color (i)

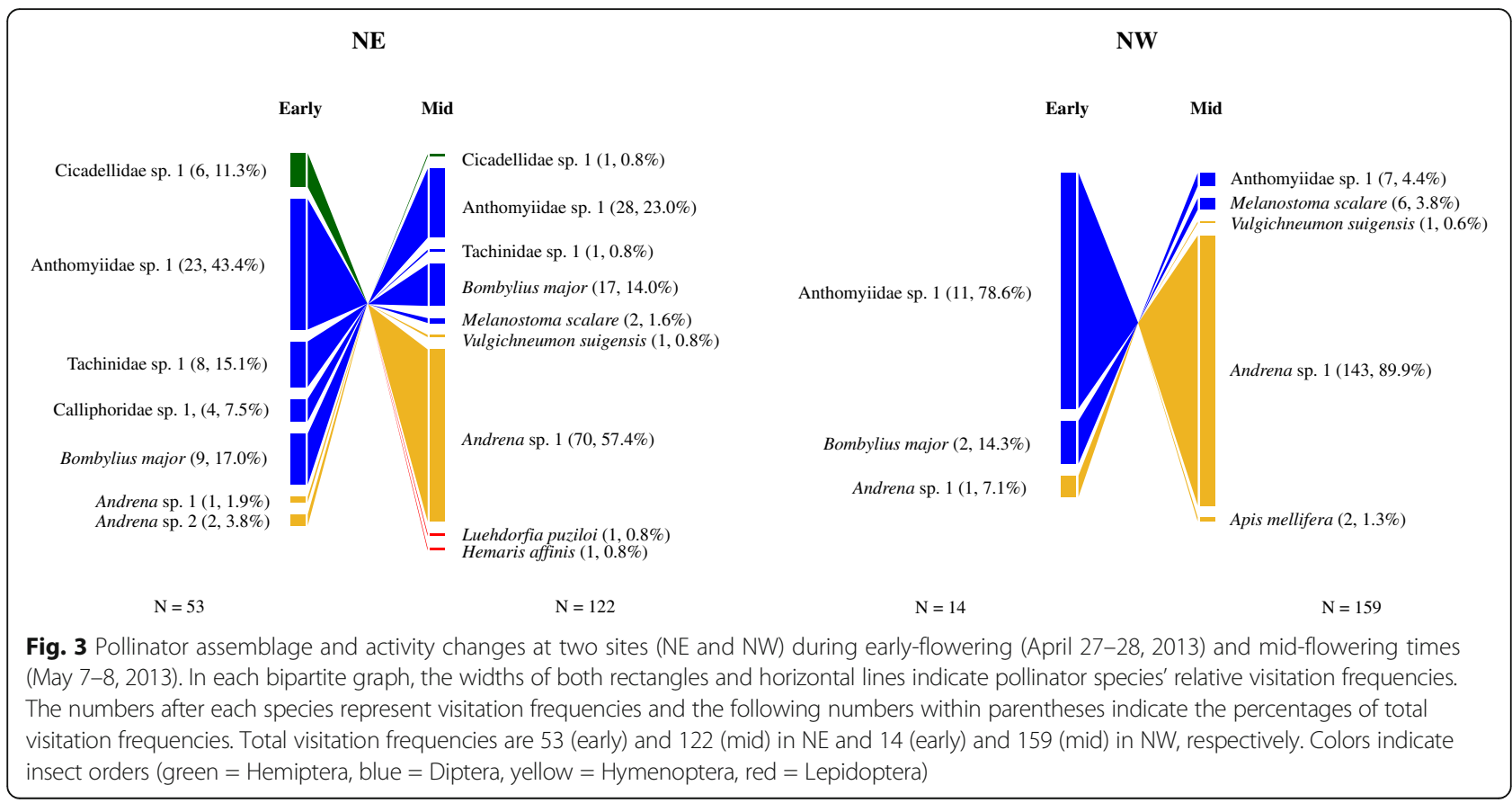


major, Melanostoma scalare (Diptera), Vulgichneumon suigensis, and Andrena sp. 1 (Hymenoptera) were observed at both sites, the other pollinators [Cicadellidae (Hemiptera), Tachinidae sp. 1, Calliphoridae sp. 1 (Diptera), Andrena sp. 2, Apis mellifera (Hymenoptera), L. puliloi, and H. affinis (Lepidoptera)] appeared only at one site (Fig. 3).

\section{Temporal changes in pollinator assemblage and activity} As the temperature rose, the number of pollinators increased at the two sites [early vs. mid $=7$ (NE) and 3 $(\mathrm{NW})$ vs. 9 (NE) and 5 (NW), Fig. 3]. Newly observed pollinators in the mid-flowering time with high temperature (mean air temperature $27^{\circ} \mathrm{C}$ ) were $M$. scalare, $V$. suigensis, Apis mellifera, Luehdorfia puliloi, and Hemaris affinis (Fig. 3). However, Calliphoridae sp. 1 and Andrena sp. 2 were no longer observed in the mid-flowering time.

There was an approximately fourfold increase in the visitation frequency toward mid-flowering times [early-flowering $(\mathrm{NE}+\mathrm{NW})$ vs. mid-flowering $(\mathrm{NE}+\mathrm{NW})=67$ vs. 281 ; Fig. 3], although the frequency was quite concordant between the two sites [NE (early + mid) vs. NW (early + mid) $=175$ vs. 173] (Fig. 3). Visitation rates were also higher in mid-flowering times than in early-flowering times (early vs. mid $=0.06$ vs. 0.20 , visits per flower per hour).

As spring progressed, the major pollinator of M. saniculifolia changed from flies to bees at both sites (Fig. 3). In the early-flowering time, flies (NE: Anthomyiidae sp. 1, Tachinidae sp. 1, Calliphoridae sp. 1, and B. major; NW: Anthomyiidae sp. 1 and B. major) were dominant, accounting for $83 \%$ and $92.9 \%$ of total visits for the NE and NW sites, respectively, whereas the opposite pattern was observed in the mid-flowering time, where bees became dominant, accounting for $58.2 \%$ and $91.8 \%$ of total visits for the NE and NW sites, respectively. Anthomyiidae sp. 1 and Andrena sp. 1 were respectively the most dominant pollinators in the low- (early) and high- (mid) temperature environment (Fig. 3). The hourly visitation frequency was strongly positively correlated to the hourly mean temperature ( $r^{2}=0.606, P<0.001, N=56$; Fig. 4).

\section{Discussion}

\section{Pollinator assemblage in the Sobaeksan population}

This is the first study to report M. saniculifolia's pollinator assemblage at high altitudes covering diverse spatial-temporal scales and temperature regimes. We found that $M$. saniculifolia has more diverse pollinator assemblage than had been reported previously (see Choi 2002). Bee pollinators that were found in the mid-flowering time with a relatively high temperature was somewhat surprising. Bees are known to be very rare in early spring at high altitudes, but they are very important for the reproductive success of $M$. saniculifolia (Lee et al. 2017). However, we acknowledge that detailed information on the whole pollinator assemblage is still lacking because we only explored a small

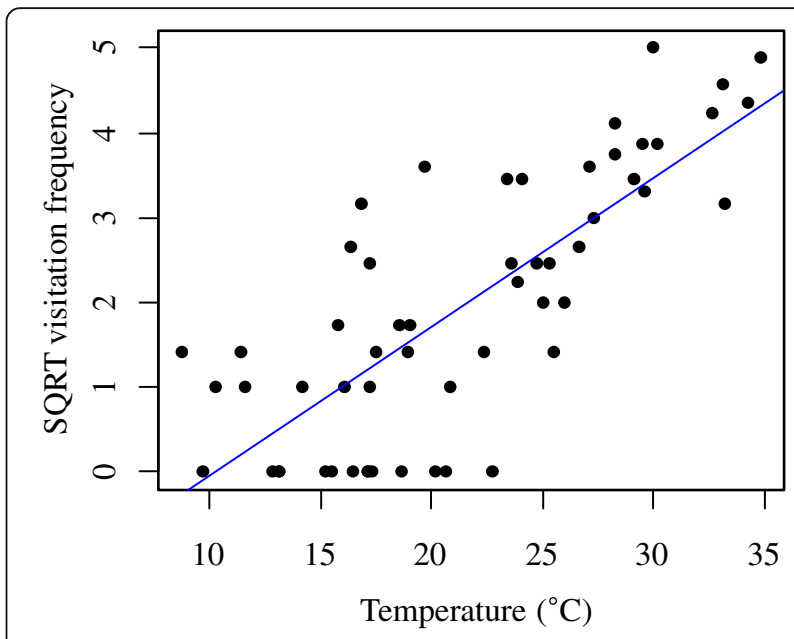

Fig. 4 The relationship between hourly mean air temperature and hourly visitation frequency in the $M$. saniculifolia population $(Y=-$ $\left.1.787+0.175 X, r^{2}=0.606, N=56, P<0.001\right)$. SQRT, square root transformation

proportion of the pollinator spectrums in a single year. Long-term monitoring covering both varying spatial and temporal scales will be valuable in further understanding the pollinator assemblage diversity and functions at high altitudes.

\section{Temperature impacts on pollinator assemblage and activity}

Temperature is one of the major abiotic factors affecting pollinator assemblage and activity at high altitudes (Primack and Inouye 1993; Totland 1994b; Thomson 2010; Straka and Starzomski 2015). Major changes in M. saniculifolia pollinator visitation patterns over the two flowering times showed a transition in dominant pollinators (flies to bees) and an increased visitation frequency (67 to 281). Because factors that could affect pollinator visitation patterns, such as snowmelt regime (Kudo 1996), composition of flowering plants (Ebeling et al. 2008), and flower density (Hegland and Boeke 2006), were almost equal in both sites, other abiotic factors, such as temperature, humidity, and wind speed, may have induced such drastic changes. Although we did not measure humidity and wind speed, temperature explained most visitation frequency variations $\left(r^{2}=0.606\right)$. The change in dominance of pollinators of M. saniculifolia also reflects the significant impact of temperature as flies and bees favor cold and warm environments, respectively (Totland 1993; Hoiss et al. 2012; Inouye et al. 2015; Zhao and Wang 2015; Wagner et al. 2016). Thus, we conclude that a drastic temperature change between early- to mid-flowering times, i.e., on average of $11.2^{\circ} \mathrm{C}$, affected $M$. saniculifolia pollinator assemblage and activity. Temperature-driven changes of pollinators also have been reported for several high altitude species (Primack 
and Inouye 1993; Totland 1994b; Thomson 2010; Straka and Starzomski 2015).

Any alterations in pollinator assemblage and activity driven by seasonal progression can provide us important insight into establishing a conservation plan for high-altitude plants in light of a warming climate. Our study suggests that different groups of pollinators may dominate under different temperature regimes. Such contrasting patterns have not been observed in some early-flowering plants (e.g., Gentiana staminea visited by bumblebees, Duan et al. 2007; Euphorbia helioscopia visited by beetles, Kim and Park 2014), and thus perhaps, pollinators of both groups of plants may be less sensitive to temperature changes. On the other hand, the impact of temperature change is important for small-bodied fly- and bee-pollinated alpine plants (seasonal gradient: Primack 1978 and Mizunaga and Kudo 2017; altitudinal gradient: Zhao and Wang 2015). M. saniculifolia heavily depends on insect pollinators for reproduction (Choi 2002; Lee et al. 2017) and is visited by both fly and bee pollinators that are known to be sensitive to temperature changes (Primack 1978; Zhao and Wang 2015; Mizunaga and Kudo 2017) and to differ in pollination effectiveness (Campbell and Motten 1985). Therefore, temperature rise during a flowering season may result in changes in the reproductive success of this rare endemic plant, as suggested in other plants (Hirao et al. 2006; Thomson et al. 2010). Since M. saniculifolia is a generalist herb with actinomorphic flowers and a relatively long flowering period (Lee et al. 2017), which might compensate for a low visitation rate in the early spring, intra-seasonal pollinator increase may contribute to mitigating pollination limitation, which has been shown in many generalist plants (Ashman et al. 2004; Gómez et al. 2007). In this regard, the increase in pollinator richness in high-temperature environment (see Fig. 3) may increase the fitness of M. saniculifolia. The fact that M. saniculifolia (Han et al. 2010) and flies (Kearns 1992; Lefebvre et al. 2018) are both vulnerable to high temperature and desiccation should be considered in the conservation of this rare endemic plant under warmer and less snowy climate. However, we still know little about how significantly the flies affect $M$. saniculifolia's reproductive success.

\section{Conclusions}

For early spring flowering plants that are likely to confront severe problems such as harsh and unpredictable weather conditions and limitation of pollinators, efficient and sufficient numbers of pollinator visitations are essential to successful reproduction. In this study, the rapid temperature increase in an approximately 10-day frame in early spring resulted in pollinator richness and activity increases of 1.4 and 4.2 times, respectively, and changes in dominant pollinators, from flies to bees. Therefore, as a spring-flowering plant highly dependent on pollinators for reproduction, the reproductive success of $M$. saniculifolia could be more sensitive to future climate change than low-altitude plants or summerflowering plants. This study provides a brief illustration of the two flowering times with contrasting temperature differences and also emphasizes that information on intra- and inter-annual variations in pollinator assemblage and activity is essential to further assess warming impacts on the reproductive fitness of $M$. saniculifolia.

\section{Abbreviations \\ NE: Northeast; NW: Northwest; SQRT: Square root}

\section{Acknowledgements}

We thank Sobaeksan National Park for allowing us to conduct the pollinator survey and Yong Hwan Park and Tae Woong Jang for the assistance with the field survey and insect identification.

\section{Funding}

This study was supported by the Sungshin University Research Grant of 2018-1-11-059/1 to HK.

Availability of data and materials

Please contact the corresponding author for data requests.

Authors' contributions

$\mathrm{HL}$ conducted the field survey and wrote the manuscript. HK wrote the final version. Both authors read and approved the final manuscript.

Ethics approval and consent to participate

Not applicable

Consent for publication

Not applicable

Competing interests

Both authors declare that they have no competing interests.

\section{Publisher's Note}

Springer Nature remains neutral with regard to jurisdictional claims in published maps and institutional affiliations.

Received: 29 October 2018 Accepted: 19 November 2018

Published online: 05 December 2018

\section{References}

Arroyo MTK, Armesto JJ, Primack RB. Community studies in pollination ecology in the high temperate Andes of central Chile II. Effect of temperature on visitation rates and pollination possibilities. Plant Syst Evol. 1985;149:187-203. Arroyo MTK, Primack R, Armesto J. Community studies in pollination ecology in the high temperate Andes of central Chile. I. Pollination mechanisms and altitudinal variation. Am J Bot. 1982;69:82-97.

Ashman T, Knight TM, Steets JA, Amarasekare P, Burd M, Campbell DR, Dudash MR, Johnston MO, Mazer SJ, Mitchell RJ, Morgan MT, Wilson WG. Pollen limitation of plant reproduction: ecological and evolutionary causes and consequences. Ecology. 2004;85:2408-21.

Bingham RA, Orthner AR. Efficient pollination of alpine plants. Nature. 1998;391:238-9.

Campbell DR, Motten AF. The mechanism of competition for pollination between two forest herbs. Ecology. 1985;66:554-63.

Choi DY. Conservation strategy based on genetic structure and mating system of rare plants, Kirengeshoma koreana Nakai and Megaleranthis saniculifolia Ohwi. Seoul: Seoul National University; 2002.

Duan YW, Zhang TF, Liu JQ. Interannual fluctuations in floral longevity, pollinator visitation and pollination limitation of an alpine plant (Gentiana straminea Maxim., Gentianaceae) at two altitudes in the Qinghai-Tibetan Plateau. Plant Syst Evol. 2007;267:255-65. 
Ebeling A, Klein A, Schumacher J, Weisser WW, Tscharntke T. How does plant richness affect pollinator richness and temporal stability of flower visits? Oikos. 2008;117:1808-15.

Gómez JM, Bosch J, Perfectti F, Fernández J, Abdelaziz M. Pollinator diversity affects plant reproduction and recruitment: the tradeoffs of generalization. Oecologia. 2007;153:597-605.

Han JW, Lee GH, Yang SG, Kang SH. Distribution of Megaleranthis saniculifolia Ohwi (Ranunculaceae) in Mt. Halla, Jeju island, Korean Journal of Plant. Resources. 2010;23:179-86.

Hegland SJ, Boeke L. Relationship between the density and diversity of floral resources and flower visitor activity in a temperate grassland community. Ecol Entomol. 2006;31:532-8.

Hegland SJ, Nielsen A, Lázaro A, Bjerknes A, Totland Ø. How does climate warming affect plant-pollinator interactions? Ecol Lett. 2009;12:184-95.

Hirao AS, Kameyama Y, Ohara M, Isagi Y, Kudo G. Seasonal changes in pollinator activity influence pollen dispersal and seed production of the alpine shrub Rhododendron aureum (Ericaceae). Mol Ecol. 2006;15:1165-73.

Hoiss B, Krauss J, Potts SG, Roberts S, Steffan-Dewenter I. Altitude acts as an environmental filter on phylogenetic composition, traits and diversity in bee communities. Proc R Soc Lond B Biol Sci. 2012;279:4447-56.

Inouye DW, Larson BMH, Ssymank A, Kevan PG. Flies and flowers III: ecology of foraging and pollination. J Pollination Ecol. 2015;16:115-33.

IPCC. 5th Annual Report. Climate change 2013: the physical science basis. New York: Cambridge University Press; 2013.

Jang SK, Cheon KS, Jeong JH, Kim ZS, Yoo KO. Environmental characteristics and vegetation of Megaleranthis saniculifolia Ohwi habitats. Korean J Environ Biol. 2009;27:314-22.

Jeong JH, Kim EH, Guo W, Yoo KO, Jo DG, Kim ZS. Genetic diversity and structure of the endangered species Megaleranthis saniculifolia in Korea as revealed by allozyme and ISSR markers. Plant Syst Evol. 2010;289:67-76.

Kearns CA. Anthophilous fly distribution across an elevation gradient. Am Midl Nat. 1992;127:172-82

Kim DI, Park KR. Pollination study of Euphorbia helioscopia (Euphorbiaceae). Korean J Plant Taxon. 2014:44:281-7.

Kim, Y.S., Kim, H., \& Son, S.W. (2016). Megaleranthis saniculifolia. The IUCN Red List of Threatened Species, 2016, e.T72136660A72136663.

Kudo G. Effects of snowmelt timing on reproductive phenology and pollination process of alpine plants. Mem Natl Inst Polar Res. 1996:51:71-82.

Lázaro A, Hegland SJ, Totland $\varnothing$. The relationship between floral traits and specificity of pollination systems in three Scandinavian plant communities. Oecologia. 2008;157:249-57.

Lee $H$, Lee $H$, Kang $H$. Mating systems and flowering characteristics of Megaleranthis saniculifolia Ohwi in a subalpine zone of Sobaeksan National Park. Korean J Ecol Environ. 2017:50:116-25.

Lefebvre V, Villemant C, Fontaine C, Daugeron C. Altitudinal, temporal and trophic partitioning of flower-visitors in alpine communities. Sci Rep. 2018;8:4706.

Mizunaga Y, Kudo G. A linkage between flowering phenology and fruit-set success of alpine plant communities with reference to the seasonality and pollination effectiveness of bees and flies. Oecologia. 2017;185:453-64.

Primack RB. Variability in New Zealand montane and alpine pollinator assemblages. N Z J Ecol. 1978;1:66-73.

Primack RB, Inouye DW. Factors affecting pollinator visitation rates: a biogeographic comparison. Curr Sci. 1993;65:257-62.

$R$ Core Team. $R$ : a language and environment for statistical computing. Vienna: $R$ Foundation for Statistical Computing; 2017. URL https://www.R-project.org/

Son DC, Cho KJ, Ko SC. Comparison of the morphology and distribution of the genus Megaleranthis Ohwi with those its relative genera (Ranunculaceae). Korean J Plant Taxon. 2011;41:315-23.

Straka JR, Starzomski BM. Fruitful factors: what limits seed production of flowering plants in the alpine? Oecologia. 2015;178:249-60.

Thomson JD. Flowering phenology, fruiting success and progressive deterioration of pollination in an early-flowering geophyte. Philos Trans R Soc B Biol Sci. 2010;365:3187-99.

Totland $\varnothing$. Pollination in alpine Norway: flowering phenology, insect visitors, and visitation rates in two plant communities. Can J Bot. 1993:71:1072-9.

Totland $\varnothing$. Intraseasonal variation in pollination intensity and seed set in an alpine population of Ranunculus acris in southwestern Norway. Ecography. 1994a;17:159-65.

Totland $\varnothing$. Influence of climate, time of day and season, and flower density on insect flower visitation in alpine Norway. Arct Alp Res. 1994b;26:66-71.
Wagner J, Lechleitner M, Hosp D. Pollen limitation is not the rule in nival plants: a study from the European Central Alps. Am J Bot. 2016;103:375-87.

Yoo KO, Lee WT, Oh YJ. External morphology and vegetation of Megaleranthis saniculifolia populations in four different habitats. Korean J Plant Resour. 1999;12:312-23.

Zhao ZG, Wang YK. Selection by pollinators on floral traits in generalized Trollius ranunculoides (Ranunculaceae) along altitudinal gradients. PLoS One. 2015;10: e0118299.

\section{Ready to submit your research? Choose BMC and benefit from:}

- fast, convenient online submission

- thorough peer review by experienced researchers in your field

- rapid publication on acceptance

- support for research data, including large and complex data types

- gold Open Access which fosters wider collaboration and increased citations

- maximum visibility for your research: over $100 \mathrm{M}$ website views per year

At BMC, research is always in progress.

Learn more biomedcentral.com/submissions 